\title{
RELAÇÕES DE GÊNERO NO COMPORTAMENTO DE COMPRA PELA INTERNET: ESTUDO DAS DIMENSÕES DO RISCO PERCEBIDO
}

\author{
GENDER RELATIONS AND THE PURCHASE BEHAVIOR BY INTERNET: \\ STUDY OF PERCEIVED RISK DIMENSIONS
}

\author{
Juliana Del Secchi ${ }^{1}$, Wesley Vieira da Silva ${ }^{2}$, \\ Jansen Maia Del Corso ${ }^{3}$ e Ubiratã Tortato ${ }^{4}$
}

Recebido em: 15/05/2011

Aprovado em:24/05/2012

\section{RESUMO}

O risco percebido é considerado um dos grandes entraves para o crescimento da Internet como canal de compras. A inovação que este artigo propõe para os estudos dessa temática é a avaliação do risco percebido nas compras pela Internet sob uma perspectiva de gênero, motivada por estudos precedentes que revelaram uma significativa maior adesão a esse comércio por parte dos homens, que seriam também mais propensos a assumir riscos. Para tanto, foi realizado um estudo quantitativo com corte transversal, por meio de surveys eletrônicas disponibilizadas na Internet. A amostra foi composta por 190 internautas (90 mulheres e 80 homens), que haviam comprado produtos e/ou serviços pela Internet nos seis meses antecedentes à pesquisa $\mathrm{e}$ que residiam em diversas regiões do Brasil e do exterior. Os resultados permitiram análises comparativas da percepção dos respondentes de cada gênero em cinco dimensões (financeiro, desempenho, psicológico, físico, social, tempo/conveniência) e no risco total que pode ser percebido nas compras realizadas pela Internet, avaliando-se a existência de diferenças estatisticamente significativas e possibilitando uma classificação destas dimensões por ordem de intensidade.

Palavras-chave: Relações de Gênero; Compras pela Internet; Risco Percebido.

\begin{abstract}
The perceived risk is regarded as one of the major obstacles to the growth of the Internet as a shopping channel. The innovation that we propose for the study of this issue is the assessment of perceived risk in Internet shopping in a gender perspective, motivated by previous studies that showed a significantly higher adherence to this trade by men, who were also more likely to take risks. To that end, we conducted a quantitative study through electronic surveys available on the Internet. The sample consisted of 190 Internet users (90 women and 80 men) who had purchased products or services over the Internet in the six months preceding the survey, residents in several regions of Brazil and abroad. The results allow comparative analysis of the perception of respondents of each gender in five dimensions (financial, performance, psychological, physical, social, time / convenience) and the total risk that can be perceived on purchases over the Internet. It was found that there exist significant statistical differences which allowed classification of these dimensions in order of intensity.
\end{abstract}

Keywords: Gender Relations; Purchase by Internet; Perceived Risk.

'Graduada em Comunicação Social - Publicidade e Propaganda - e Mestre em Administração pela Pontifícia Universidade Católica do Paraná (PUC-PR), Brasil. Professora das Escolas de Negócios e de Comunicação e Artes da PUCPR. E-mail: juliana.del@pucpr.br.

${ }^{2}$ Graduado em Ciências Econômicas pela UFA. Mestre e Doutor em Administração pela Universidade Federal de Santa Catarina (UFSC). Coordenador e Professor do Programa de Pós-Graduação em Administração da Pontificia Universidade Católica do Paraná (PUCPR), Brasil. E-mail: wesvsilva@ gmail.com.

${ }^{3}$ Mestre em Administração pela Fundação Getúlio Vargas - Rio de Janeiro (FGV-RJ). Doutor em Ciências de Gestão pela ESADE-Barcelona. Professor do Programa de Pós-Graduação em Administração da Pontificia Universidade Católica do Paraná (PUC-PR), Brasil. E-mail: del.corso@pucpr.br.

${ }^{4}$ Graduado e Mestre em Administração pela Universidade Federal do Paraná (UFPR). Doutor em Engenharia de Produção pela Universidade de São Paulo (USP). Professor do Programa de Pós-Graduação em Administração da Pontifícia Universidade Católica do Paraná (PUC-PR), Brasil.. E-mail: ubirata.tortato@pucpr.br. 


\section{Introdução}

$\mathrm{O}$ rápido crescimento do comércio eletrônico pela Internet nos últimos anos e a constatação de que o varejo eletrônico e o tradicional são significativamente diferentes têm despertando grande interesse dos pesquisadores para o estudo do comportamento dos consumidores desse canal. A decisão de comprar pela Internet, como explicam Cordeiro, Silveira e Benevides (2004), expõe o consumidor a uma série de análises comparativas de custos e benefícios. Os principais benefícios estariam relacionados à economia de tempo, conveniência, variedade de produtos disponíveis a qualquer hora e local, além da facilidade de realizar comparações. Por outro lado, vários estudos apontam que grande parte dos consumidores percebe níveis mais altos de risco em situações de compra on-line do que no comércio convencional. Uma vez que o risco percebido poderia, dessa forma, representar um obstáculo para o crescimento da internet como canal de compras, a compreensão desse fenômeno tem se revelado importante.

Frank Farley (1986, p. 47) argumenta que há consumidores que apresentam maior propensão a assumir riscos, e que esse grupo seria predominantemente masculino, graças à presença do hormônio testosterona. Estudos realizados por Viera, Viana e Echeveste (1998) indicaram que as mulheres tendem a atribuir maior importância aos fatores relacionados à confiança e segurança em situações de compra pela Internet.

Solomon (2008) ressalta que a identidade de gênero é um componente fundamental no autoconceito do consumidor e nas decisões de consumo e, por isso, não deve ser negligenciada pelos estudiosos e profissionais de Marketing. Nesse contexto, a inovação que este artigo propõe para os estudos dessa temática é a avaliação do risco percebido nas compras pela Internet sob uma perspectiva de gênero.
A despeito da existência de pesquisas que versam sobre os riscos percebidos pelos consumidores do comércio eletrônico pela Internet - o que já denota sua relevância como objeto de estudo - não foram encontradas pesquisas testando a relação entre o gênero e a percepção do risco nesse ambiente.

Ressalta-se que, apesar do gradativo aumento de participação das mulheres no comercio eletrônico, o canal ainda está longe de ser preterido pelas consumidoras. "O comércio eletrônico não é capaz de gerar o impulso de compra da mulher (...) enquanto que o homem, que resiste às 'tentações' do comércio convencional, parece tornar-se mais vulnerável aos apelos eletrônicos" (SILVA et al, 2000, p. 56).

Motivado por essa constatação e pelo indício de que os homens seriam mais propensos a assumir riscos em função de características biológicas peculiares, este estudo tem por objetivo principal averiguar se a variável gênero revelar-se-á significativa na percepção de risco e consequente decisão de compra pela Internet. Diante disso, a justificativa teórica concentra-se na tentativa de agregar conhecimentos que permitam contribuir para a consolidação dos estudos na temática, notadamente no que tange uma maior compreensão sobre o perfil do consumidor do comércio eletrônico pela Internet.

A justificativa prática para sua realização baseia-se na premissa de que o aumento no risco percebido está relacionado a uma menor probabilidade de realizações de compras pela Internet, bem como a uma restrição na comercialização a apenas algumas categorias de produto. O risco percebido é, portanto, apontado como um importante obstáculo para a consolidação da Internet como canal de compras. Diante desse contexto, pretende-se que as conclusões desta pesquisa forneçam subsídios para que as empresas que atuam ou pretendem atuar nesse ramo identifiquem as dimensões do risco percebido que mais 
afetam seu público potencial e, assim, tenham condições de implementar medidas, favorecendo sua redução.

A fim de alcançar o objetivo proposto, este estudo identificará os tipos ou as dimensões de riscos percebidos pelos consumidores do comércio eletrônico pela Internet apresentados na literatura; apreenderá a percepção de internautas quanto às dimensões de riscos envolvidos na compra pela internet; analisará se há diferenças significativas relativas às dimensões de riscos percebidos manifestadas pelo grupo de homens e mulheres; e identificará quais tipos de riscos são percebidos com mais intensidade por cada estrato.

A seguir, será apresentada uma revisão teórica concernente ao comércio eletrônico pela Internet; aos conceitos de risco percebido e às suas dimensões na compras pela Internet; à abordagem do gênero nos estudos do Comportamento do Consumidor; à influência do gênero na determinação do perfil do consumidor que compra pela Internet; e à relação dos homens e mulheres com o risco percebido.

\section{Revisão teórica}

\subsection{Comércio eletrônico pela internet}

O conceito de comércio eletrônico é mais abrangente do que geralmente se apresenta, pois, muitas vezes, é tratado simplesmente como sinônimo de vendas pela Internet. A loja virtual na Internet é apenas uma das várias formas de atender remotamente o público, com entrega em domicílio, a exemplo do que ocorre com o telefone, fax ou programas de mensagens instantâneas. É uma ferramenta de atendimento de pedidos que se dirige a um público específico - os internautas - e que tem por característica permitir que os usuários realizem suas compras a qualquer hora e em qualquer dia da semana. "Em outras palavras, comércio eletrônico refere-se à compra e venda através de meios eletrô- nicos, seja via Internet ou não" (SILVA et al., 2000, p. 44).

A despeito dessa distinção, o que se pretende enfatizar, neste estudo, é o comércio eletrônico pela Internet, que, nos últimos anos, tem alcançado altos índices de crescimento, destacando-se como um importante meio de compras e despertando interesse para o estudo do comportamento desse consumidor. Enfoque especial é dado à análise de fatores motivadores e condicionantes de sua adoção, como explica Hernandez (2003).

Em um estudo sobre os atributos determinantes da utilização da Internet como canal de compras, Amaral e Nique (2000) concluíram que, entre os principais benefícios percebidos pelos consumidores estão, entre outros: a possibilidade de realização de compras a qualquer hora, a economia de tempo, a ausência da necessidade de deslocamento físico, a comodidade, a oferta de produtos não disponíveis no mercado local, a possibilidade de comparação de preços e a ausência de pressão psicológica exercida pelos vendedores nas lojas tradicionais.

Entretanto, a internet também tem suas limitações. Além da impossibilidade de experimentação, que faz com que a compra de certos tipos de produtos tornese menos atrativa, a insegurança é apresentada pela maioria dos autores (SILVA et al., 2000; HERNANDEZ, 2003; SOLOMON, 2008) como um dos principais entraves do desenvolvimento desse meio como canal de compras.

Algumas características intrínsecas da Internet contribuem para a percepção de risco, tais como: a inexistência de um interlocutor para sanar as dúvidas ou orientar o comportamento do consumidor; a impossibilidade de o consumidor inspecionar fisicamente o produto a ser adquirido e a necessidade de confiança no varejista de que a mercadoria será entregue conforme foi solicitado; a dificuldade de diferenciação entre negócios legítimos e ilegais na rede; a falta de uma sólida legislação 
de proteção ao consumidor; bem como o temor da perda de privacidade, do furto do número do cartão de crédito, do tempo gasto na procura dos produtos por questões técnicas ou por problemas com a entrega do que foi encomendado (HERNANDEZ, 2003; ALVARES, 2004; KOVACS e BARBOSA, 2005).

\section{$2.2 \mathrm{O}$ risco percebido}

O conceito de risco percebido foi introduzido na literatura de Marketing e Comportamento do Consumidor por Raymond Bauer, na década de 60 . Como explica ALVARES (2004, p. 33), o construto foi originalmente definido pelo autor "como uma combinação de incerteza e da seriedade das consequências envolvidas na decisão de compra".

Em outras palavras, tratava-se de um conceito bidimensional relacionando incertezas - probabilidade subjetiva de algo - e consequências, como complementam Kovacs e Espírito Santo (2008), que ressaltam a ênfase dos estudos de Bauer sobre o risco percebido (subjetivo) e não sobre o risco real (objetivo). Enquanto o risco real pode ou não ser percebido pelo indivíduo, o risco percebido pode até não existir na realidade, mas existe na mente do indivíduo.

Peter e Ryan (1976) apresentaram como sendo uma tendência dos modelos formais de risco percebido esta descrição do construto como resultado do produto de uma incerteza (probabilidade) de perda/prejuízo e da consequência (ou importância) dessa perda/ prejuízo. Quase trinta anos depois, Alvares (2004) continuou identificando, nas definições de outros autores da área (e.g. ASSARAEL, 1995; VOLLE, 1995), a menção aos mesmos dois componentes.

Peter e Tarpey (1975) abordavam a questão da multidimensionalidade do construto ao afirmar que, desde sua introdução no comportamento do consumidor, o risco percebido foi definido como um fenômeno multifacetado (e.g. BAUER, 1960; CUNNINGHAM, 1967; ROSELIUS, 1971; JACOBY E KAPLAN, 1972). Considerando a dualidade e as múltiplas dimensões do conceito, Peter e Tarpey (1975) apresentaram o seguinte modelo:

$$
\mathrm{OPR}_{\mathrm{\jmath}}=\mathrm{f} \sum_{\mathrm{i}=\mathbf{1}}^{\mathrm{n}}\left(\mathrm{PL}_{\mathrm{ij}} \cdot \mathrm{IL}_{\mathrm{ij}}\right)
$$

Onde $\mathrm{OPR}_{\mathrm{j}}=$ risco percebido total para a marca $\mathrm{j}$

$\mathrm{PLij}_{\mathrm{j}}=$ probabilidade de perda/prejuízo para a compra da marca $\mathrm{j}$

$\mathrm{IL}_{\mathrm{ij}}=$ importância da perda/prejuízo i da compra da marca j

$\mathrm{n}=$ dimensões do risco

Figura 1 - Modelo de mensuração do risco percebido

Fonte: Traduzido de Peter e Tarpey (1975, p.30).

Peter e Tarpey (1975) descrevem o risco percebido não apenas como uma função multiplicativa de probabilidade de perda/prejuízo e importância de perda/prejuízo, mas também como um modelo aditivo das seguintes dimensões do risco: financeiro, desempenho, psicoló- gico, físico, social, tempo/conveniência, pois, segundo os autores, esses são os tipos mais amplamente discutidos na literatura da área.

Mais recentemente, Brasil, Sampaio e Perin (2008) continuam corroborando que esses são os principais ti- 
pos riscos considerados e mensurados, apesar de não haver consenso entre os estudiosos. Essas dimensões serão apresentadas no tópico a seguir, com ênfase no ambiente de compras pela Internet, em consonância com os objetivos do presente estudo.

2.3 As dimensões do risco percebido nas compras pala internet

Como anteriormente introduzido, o risco percebido nas compras pela Internet tem se revelado um importante objeto de estudo nas pesquisas de Marketing e Comportamento do Consumidor, uma vez que, como revelam várias pesquisas, a exemplo de Lasch (1998), muitos consumidores estão preocupados com segurança e privacidade quando utilizam a Internet para comprar produtos ou contratar serviços e deixam de realizar transações on-line por causa dos riscos.

Diante desse cenário, o conceito de risco percebido, difundido na literatura de Marketing há mais de cinco décadas, vem sendo utilizado para avaliar a adoção do comércio eletrônico pela Internet por parte dos consumidores. Entretanto, Kovacs e Espírito Santo (2008, p. 12) apregoam que os estudos ainda são embrionários, destacando a "necessidade de contemplar tipologias de riscos específicas para meios de compra", uma vez que a maior parte da literatura ainda estaria concentrada na análise de categorias de produtos, independente do canal ou meio pelo qual a experiência foi realizada.

É possível supor que as compras pela Internet desencadeiem novos tipos de riscos, tais como o risco de privacidade e segurança nas informações transmitidas. Os estudos indicam, por exemplo, que usuários da Internet temem que as empresas utilizem indevidamente, vendam ou distribuam suas informações pessoais. Também mencionam possíveis influências provindas de notícias veiculadas na mídia a respeito de fraudes cometidas por hackers, bem como o medo de que o número de cartão de crédito seja fraudado e de realizar o pagamento adiantado de um produto sem a garantia de entrega (KOVACS E FARIAS, 2001; CHEN E BARNES, 2007; KOVACS E ESPÍRITO SANTO, 2008).

Hernandez $(2002$, p. 7) também já dizia que "Além dos riscos inerentes às práticas comerciais, comuns às transações convencionais, o comprador eletrônico também está sujeito aos riscos de privacidade e segurança da transação que a Internet oferece, riscos geralmente não associados aos mercados convencionais". Para o autor, as lojas eletrônicas que atuam exclusivamente pela Internet estariam em desvantagem quando comparadas a outras que também atuam no varejo tradicional em relação à confiança percebida pelo consumidor, já que a familiaridade com a marca seria um atenuante dos riscos percebidos.

Em outro artigo, Hernandez (2003) aborda o aspecto da experiência de compra pela Internet. Segundo ele, enquanto alguns autores defendem que o risco percebido aumenta à medida que o indivíduo utiliza a Internet, pois ele se tornaria mais consciente dos riscos, outros argumentam que a experiência de uso favorece o discernimento entre os riscos reais e os fictícios, o que tenderia a resultar em uma diminuição na percepção do risco.

Em um recente estudo realizado com estudantes da Malásia, Ling et al. (2011) procuraram compreender e avaliar os impactos da tecnologia percebida e do risco percebido na confiança dos consumidores aos varejistas on-line, bem como essa confiança estaria relacionada à intenção de compra. Os estudiosos descobriram que a tecnologia percebida, assim como a percepção de risco, estão positivamente relacionadas à confiança on-line; e que a confiança e a tecnologia estão positivamente relacionadas com à intenção de compra. Neste estudo, o construto risco percebido foi considerado como resultante de 
duas variáveis: segurança e privacidade percebida. Portanto, quanto maior a segurança e a privacidade percebidas pelo consumidor on-line, maior sua confiança no varejista - o risco percebido seria, portanto, um antecedente da satisfação.

Vale ressaltar, contudo, que os próprios autores já alertam para a falta de consenso na literatura sobre a relação entre risco percebido e confiança on-line. Enquanto alguns estudiosos apregoam uma correlação positiva e de antecedência (tal como Ling et al.), outros defendem que tal relação é de consequência, ou seja, que a confiança seria um antecedente do risco percebido, ou seja, os consumidores percebem menores riscos quando se relacionam com lojas nas quais existe confiança prévia.

Assim como ocorre na literatura sobre risco percebido, é possível perceber, também no concernente aos riscos percebidos no ambiente de compras pela Internet, a ausência de um consenso entre os autores sobre as dimensões que devem ser consideradas. A despeito dessa dificuldade, serão apresentados, a seguir, os principais tipos de risco percebido encontrados na literatura relacionada ao comércio eletrônico pela Internet.

\subsubsection{Risco financeiro}

$\mathrm{O}$ risco financeiro refere-se, segundo Mowen e Minor (2003), a quaisquer resultados que possam prejudicar financeiramente o consumidor, relacionados à perda de bens ou de dinheiro, ou seja, ao risco de que determinada decisão de compra deixe o consumidor em uma situação financeira desfavorável. Especificamente no caso das compras realizadas pela Internet, os principais indicadores do risco financeiro estariam, segundo Kovacs e Farias (2001), relacionados a uma possível interceptação de dados financeiros e/ou ao fato de que esse canal não permite que o consumidor negocie o preço dos produtos e serviços adquiridos.
Cordeiro, Silveira e Benevides (2004) corroboram a percepção de prejuízo financeiro em função de possíveis fraudes, especialmente relacionadas aos cartões de crédito, bem como incluem a possibilidade do não recebimento do produto como indicador dessa dimensão. Em sua pesquisa, os autores concluíram que se trata de um tipo de risco altamente representativo na percepção dos respondentes, com forte influência na decisão de compra pela Internet.

\subsubsection{Risco de desempenho (Perfor- mance) ou funcional}

$\mathrm{O}$ risco de desempenho (perfomance) ou funcional refere-se à "possibilidade de que o produto não funcione como esperado e/ou não proporcione os benefícios desejados" (GREWAL et al., 1994, p.145). De forma mais objetiva, trata do "risco de que o produto não apresente o desempenho esperado" (MOWEN; MINOR, 2003, p. 104).

Segundo Kovacs e Farias (2001), esse tipo de risco pode ser desencadeado nas compras pela Internet em função da impossibilidade de experimentação do produto adquirido, ou seja, como não é possível experimentar, tocar ou sentir o que está comprando, o consumidor pode perceber o risco de comprar um produto que não esteja de acordo com suas expectativas.

\subsubsection{Risco social}

O risco social está relacionado ao julgamento de terceiros, tais como amigos ou familiares, que podem considerar que o consumidor não fez uma boa escolha, quer seja na decisão de compra de um produto propriamente dito, quer seja na atitude de compra por um determinado canal, e podem, inclusive, menosprezá-lo por tal decisão. Está, portanto, relacionado à questão da estima e da autoconfiança do indivíduo (MOWEN E MINOR, 2003; ALVARES, 2004). 
Além disso, o risco social também está relacionado à perda da privacidade e disseminação de dados pessoais, como explicam Kovacs e Farias (2000, p. 8):

Ao enviar dados pessoais pela Internet o consumidor fica exposto também ao comércio destes dados pelas próprias empresas com as quais estariam efetuando compras, desencadeando assim o receio do fim da privacidade (...) podendo surgir o risco social onde a privacidade seja invadida sem o devido conhecimento e consentimento prévio (KOVACS; FARIAS, 2000, p. 8).

Em função da impessoalidade da compra que é intermediada pelo computador, o risco social também é comumente relacionado a uma diminuição do senso de comunidade no que se refere à questão da interação social (KOVACS; FARIAS, 2001).

\subsubsection{Risco psicológico}

Segundo Mowen e Minor (2003, p.104), representa o "risco de que o produto diminua a imagem que o consumidor tem de si mesmo"; ou de que a compra afete "o bem-estar mental do usuário" (KOTLER; KELLER, 2006, p.196). Trata-se, portanto, da forma como o consumidor se percebe após a realização de uma compra, o risco de desapontar-se consigo por não ter feito uma escolha satisfatória ou coerente com sua autoimagem. (CORDEIRO; SILVEIRA E BENEVIDES, 2004; ALVARES, 2004).

Kovacs e Farias (2001) utilizaram a dificuldade de decisão em razão da variedade de opções; o arrependimento da compra efetuada; e o possível comprometimento da autoimagem caso o indivíduo não consiga efetuar a transação eletrônica com sucesso, como indicadores para avaliar a percepção dos consumidores nesta dimensão de risco. Cordeiro, Silveira e Benevides (2004) sugerem que a compra pela Internet potencializa a percepção do risco psicológico porque a possibilidade de insatisfação com a compra efetuada tenderia a aumentar por esse meio.

\subsubsection{Risco de tempo/conveniência}

A questão do tempo ou conveniência é indicada como um dos principais fatores determinantes na decisão de compra on-line, que tanto pode ser percebida como um benefício, quanto pode desencadear uma sensação de risco. Refere-se ao tempo, à conveniência e à energia despendidos com ajustes, reparos e substituições, em função de algum insucesso na compra ou em relação ao produto (ROSELIUS, 1971).

Solomon (2008) chama a atenção ao fato de que o tempo, em geral, é percebido como um recurso restrito, sendo que essa escassez lhe confere valorização por parte dos indivíduos, ou seja, as pessoas percebem que o tempo é um recurso limitado e que não pode ser desperdiçado.

Uma pesquisa realizada por Cordeiro, Silveira e Benevides (2004) revelou que a representatividade atribuída pelos respondentes a esta dimensão de risco foi superior na Internet do que a atribuída ao ambiente de compra tradicional. Segundo os autores,

isso sugere que os consumidores sentem uma maior dificuldade para efetuar a troca de um produto adquirido pela Internet, visto que essa troca poderá demandar muito mais tempo, considerando-se o contato a ser feito com a loja, a devolução do produto à transportadora e o tempo de espera do recebimento de um novo produto (CORDEIRO; SILVEIRA; BENEVIDES, 2004, p. 9).

Para Kovacs e Farias (2001), o risco de tempo está relacionado a um possível não cumprimento do prazo de entrega pela empresa, à demora em caso 
de eventuais trocas ou ao tempo de execução da compra pela Internet.

\subsubsection{Risco físico}

De acordo com Mowen e Minor (2003), trata-se do "risco de que o produto prejudique fisicamente o comprador"; ou ainda relaciona-se a qualquer "ameaça ao bem-estar físico ou à saúde do usuário ou de outras pessoas" (KOTLER; KELLER, 2006, p. 196). Por outra perspectiva, Kovacs e Farias (2001) apresentam o risco físico como um possível dano sofrido pelas mercadorias ao serem transportadas inadequadamente. Entretanto, a exemplo de Hor-Meyll (2004), a maioria dos autores assume a primeira definição e desconsidera este risco ao avaliar as compras pela Internet, por acreditar que essa transação não apresenta ameaça à integridade física dos indivíduos.

$2.4 \mathrm{O}$ gênero nos estudos do comportamento do consumidor

Como explica Peretti (2011), o gênero é um objeto de estudo nas mais diversas áreas do conhecimento, tais como antropologia, sociologia, historia, teologia, psicanalise, linguística, medicina, direito, entre outras. A autora ainda destaca que

O Gênero é um conceito-chave hoje para a ciência, já estando em uso há pelo menos três decênios. Das ciências humanas e sociais, esse conceito vem atravessando muitas fronteiras além das disciplinares: rompeu os muros da academia, invadiu os movimentos sociais e as práxis de todas as ordens, ocupa espaço crucial nas discussões internacionais e é tema e demanda central das varias agências nacionais e globais para o financiamento de pesquisa e desenvolvimento (PERETTI, 2011, p. 14).

Em se tratando do Comportamento do Consumidor, diferenças entre o comportamento de compra masculino e feminino vêm sendo estudadas há décadas, com indícios de trabalhos seminais em meados da década de 40 , segundo argumentam Bacellar, Gouveia e Miranda (2006). Solomon (2008) relata que essa diferenciação de gênero é despertada bem cedo na vida de um indivíduo, exemplificando com a produção de fraldas em duas versões de cores: rosa para as meninas e azul para o uso dos meninos.

Um dos assuntos recorrentes e polêmicos dentro dessa temática é a influência de predisposições biológicas versus explicações de cunho cultural no comportamento do consumidor. Segundo a perspectiva biológica, os homens e mulheres difeririam em seus comportamentos em função de diferenças hormonais, cromossomos e lateralização do cérebro.

Do outro lado, estão aqueles que defendem que diferenças sociais são mais relevantes, como por exemplo, $\mathrm{Ca}$ terall e Maclaran (2002), para os quais as diferenças de gênero seriam resultantes de questões culturais e não meramente de condições naturais ou biológicas, definindo-o como uma categoria sociocultural relacionada às maneiras pelas quais homens e mulheres socializam-se em papéis masculinos e femininos. Tal proposição é coerente com o proposto por Peretti (2011, p. 14): "não podemos compreender o feminino e o masculino como paradigmas simplesmente biológicos ou culturais, porque essa categoria parte de uma visão relacional, em que os sujeitos são considerados atores históricos, dotados de corpos e mentes construídos na vida social". A despeito da ausência do consenso sobre até que ponto as diferenças de gênero seriam inatas ou culturalmente moldadas, Solomon (2008) alerta que essa identidade é um componente fundamental no autoconceito do consumidor e nas decisões de consumo e, por isso, não devem ser negligenciadas pelos estudiosos e profissionais de Marketing.

Blackwell, Miniard e Engel (2005, p. 397) aproximam-se do assun- 
to, abordando a relevância da análise do papel da mulher como consumidoras ao dizer que "Os gerentes de marketing sempre tiveram interesse nas mudanças de estilo de vida que ocorrem entre as mulheres, porque as consumidoras compram muitos produtos - para elas e para suas famílias".

Paco Underhill, considerado como um dos fundadores da ciência do consumo, já afirmava, desde a primeira edição de sua obra intitulada Vamos às Compras: a ciência do consumo, que "homens e mulheres diferem em quase tudo; portanto, por que não haveriam de diferir também nas compras?" (1999, p. 90; 2009; p. 109). Dez anos depois - tendo percorrido o mundo com traduções em 27 idiomas - a obra foi revisada e atualizada, mas o autor manteve intacta a citação original, demonstrando que o tempo não apagou a importância relativa aos estudos que contrapõem o comportamento de compra e consumo de homens e mulheres.

Bacellar, Gouveia e Miranda (2006), que se debruçaram a estudar o papel dos homens em situações de compra de supermercados, alertam para a necessidade de considerar as mudanças socioculturais e seus reflexos no comportamento de consumo de homens e mulheres, pois os papéis masculinos e femininos estão em constante transformação. Underhill (2009, p. 110) corrobora o fato de que "à medida que mudam os papéis das mulheres, muda também seu comportamento de compra.". O autor critica o pensamento convencional de que o homem não gosta de fazer compras, e que, por isso, grande parte do varejo procura dirigir os esforços de experiência de compra no pontode-venda às mulheres.

Os homens agora fazem mais compras do que nunca e essa tendência continuará a crescer. Permanecendo solteiros por um tempo cada vez maior, aprendem a adquirir coisa que seus pais nunca tiveram que com- prar. Além disso, casando-se com mulheres que trabalham tanto e tão arduamente quanto eles, são forcados a compartilhar mais o encargo das compras. Os fabricantes, varejistas e projetistas de displays que prestam atenção ao jeito dos homens e que estão dispostos a adaptar a experiência de compra a eles terão uma vantagem neste século XXI (UNDERHILL, 2009, p. 112).

Underhill (2009) dedica parcela significativa da sua obra para descrever aspectos peculiares aos comportamentos de compra e consumo de ambos os gêneros. Desde o instinto de caça atribuído aos homens durante grande período da história, que se reflete na objetividade, na impaciência e no menor tempo na busca e na avaliação das alternativas, até os produtos típicos por eles consumidos, passando pelos papéis de compra predominantemente atribuídos aos homens, o autor descreve resultados de diversas observações e experimentos, sem deixar de justificá-los por condições naturais, biológicas ou socioculturais. De forma semelhante, associa comportamentos femininos à condição pré-histórica das mulheres como coletoras de raízes, nozes e frutos do mar, demonstrando uma inclinação para as compras habilidosas, que requerem observar e avaliar alternativas com maior prudência e atenção. Ressalta a compra como atividade social, divertida e prazerosa:

As mulheres são coletoras que extraem um imenso prazer do ato de olhar. Portanto, duas mulheres podem passar o dia inteiro em um shopping center sem comprar coisa alguma e, ainda assim, se divertir muito. As mulheres, de fato, tem mais afinidade com o conceito daquilo que imaginamos seja "fazer compras"; percorrer calmamente as lojas, examinando mercadorias, comparando produtos e valores, interagindo com vendedores, fazendo perguntas, experimentando coisas e, finalmente, comprando (UNDERHILL, 2009, p. 110). 
Em síntese, ao observar e relatar peculiaridades inerentes ao comportamento de compra de homens e mulheres, Underhill (2009) fornece subsídios para que os fabricantes, varejistas e profissionais de marketing possam tornar as lojas e os produtos mais atrativos para seus públicos.

$2.5 \mathrm{O}$ gênero e o perfil do consumidor pela Internet

De acordo com o e-bit, empresa referência no monitoramento e disseminação de informações sobre o comércio eletrônico no Brasil, a participação das mulheres nas compras virtuais aumentou significativamente na última década: em 2001, elas representavam 39\%; em 2005, 42\%; e, em 2010, sua participação tornou-se equivalente a de homens dentre os consumidores virtuais (E-BIT, 2011). Entretanto, apesar desse aumento, o comércio de rua e as lojas em shoppings ainda são os locais de compra preferenciais para mais de $80 \%$ das mulheres (preteridos por $48 \%$ e $33 \%$ delas, respectivamente). O estudo sobre hábitos de consumo feminino realizado pelo Ibope e divulgado em 05 de março de 2010 revelou, ainda, que apenas $6 \%$ das brasileiras têm o hábito de comprar pela internet. Foram realizadas entrevistas com 19.456 pessoas entre os meses de agosto de 2008 e agosto de 2009 (G1, 2010).

Ainda em 1996, quando a proporção de mulheres no comércio eletrônico era aproximadamente de 2 homens para 1 mulher, Lynch e Lundquist (1996, p. 121) relatavam que as mulheres sentiam-se importunadas, rejeitadas, e o comércio eletrônico tinha pouca credibilidade para as consumidoras.

A despeito das variações percentuais, a baixa adesão ao comércio eletrônico na Internet tem se confirmado, o que desperta interesse em descobrir quais os fatores contribuem para esse cenário. Silva et al. (2000, p. 56) sugerem que:
Talvez, pelo menos do que diz respeito à Internet, o mito do "consumismo feminino" tenha sido desbancado. Isso pode ser devido às características intrínsecas das mulheres, que as fazem preferir o comércio convencional, em que podem tocar, sentir, experimentar o produto. Esta é uma relação interessante para ser analisada, pois o comércio eletrônico não é capaz de gerar o impulso de compra da mulher, irresistível à grande maioria delas quando fisicamente próximas do seu objeto de desejo, enquanto que o homem, que resiste às "tentações" do comércio convencional, parece tornar-se mais vulnerável aos apelos eletrônicos (SILVA et al., 2000, p. 56).

Além das questões de experimentação e das compras por impulso evidenciadas por Silva et al. (2000), outro aspecto passível de análise é o papel do risco percebido, a fim de averiguar se essa variável está ou não relacionada a uma diferença na atitude de compra dos homens e mulheres pelo comércio eletrônico, que é justamente a relação que o presente estudo se propôs a analisar. Essa suposição baseia-se em uma possível diferença na propensão de assumir riscos, manifestada por homens e mulheres, como será apresentado a seguir.

2.6 Propensão ao risco: homens x mulheres

A propensão ao risco é definida como uma tendência individual de assumir ou evitar riscos. Os indivíduos com maior tendência a assumir riscos são apresentados pela literatura como caçadores de riscos e usualmente definidos como "Tipo T" ou "Grande T".

No artigo intitulado Word of the Type T Personality, Farley (1986) apresenta resultados de experimentos realizados por ele, bem como por outros estudiosos na área da Psicologia, acerca da Personalidade do Tipo T, tais como 
Daniel Berlyne, Marvin Zuckerman e Hans Eysenck. No extremo de um continum, o indivíduo do tipo T ("grande T") apresenta maior tendência a buscar sensações e experiências intensas, estimulantes, e maior predisposição a assumir riscos. No outro extremo, personalidade do tipo $t$ (pequeno T) é característica daqueles que preferem evitar riscos e situações não familiares, que se asseguram naquilo que é mais previsível. Farley (1986) explica que o grupo dos caçadores de riscos é predominantemente masculino e sugere que esse tipo de comportamento pode estar ligado ao hormônio testosterona.

Em um estudo exploratório sobre o comércio eletrônico pela Internet, Viera, Viana e Echeveste (1998) concluíram que a amostra pesquisada revelou a existência de diferenças significativas entre homens e mulheres quanto ao grau de importância atribuído ao fator confiança e segurança, sendo que as mulheres tenderiam a atribuir uma maior importância para essa questão. $\mathrm{O}$ fator foi mensurado pelos indicadores segurança no pagamento, no prazo de entrega e na confiabilidade dos fornecedores.

\section{Metodologia da pesquisa}

\subsection{Caracterização da pesquisa}

Este estudo teve caráter descritivo, foi conduzido em fase única e com corte transversal. Como explicam Hair Jr et al. (2005), os planos de pesquisa descritiva geralmente são estruturados e especificamente criados para medir as características descritivas em uma questão de pesquisa. Nesse caso, a pesquisa investigou como estão relacionadas as variáveis gênero e a percepção do risco nas compras pela Internet. Trata-se de um estudo quantitativo, realizado por surveys de amostra (levantamento de dados primários a partir de indivíduos) que, segundo Hair Jr et. al. (2005), caracterizam os estudos transversais.

\subsection{Coleta e tratamento de dados}

A coleta de dados de survey foi realizada pela Internet, em um site especialmente desenvolvido para essa finalidade, no período de dois de agosto a primeiro de setembro. $\mathrm{O}$ questionário foi composto por 27 questões, sendo 7 primeiras de filtro e identificação, e as demais para mensuração das dimensões do risco percebido. Os respondentes foram expostos a uma situação hipotética de compra de um notebook e solicitados a avaliar a probabilidade de ocorrência de determinadas perdas/prejuízos e o grau de importância atribuída a estas.

A operacionalização da coleta de dados envolveu o envio de e-mails para multiplicadores em diversas empresas e instituições educacionais, encaminhando-os ao site no qual o questionário foi hospedado, bem como a divulgação da pesquisa em comunidades virtuais. Aos destinatários, foi solicitado que reencaminhassem o e-mail a outros respondentes que se correspondiam ao perfil da amostra.

A população desta pesquisa foi composta por homens e mulheres maiores de 18 anos, que haviam comprado ao mínimo uma vez algum produto ou contratado algum serviço pela Internet nos seis meses antecedentes à pesquisa. Para a seleção dos elementos, foi realizada uma amostragem não probabilística, que se justifica, nesse caso, pela dificuldade de identificar e contatar todos os respondentes potenciais da pesquisa, bem como por restrições financeiras e orçamentárias que inviabilizariam a realização de uma amostragem probabilística. As técnicas não probabilísticas utilizadas foram: amostragem por conveniência; por quotas compostas por dois estratos (homens e mulheres); e bola-de-neve.

Dos 212 respondentes, foram desconsiderados 42 questionários incompletos ou inválidos, resultando em uma amostra real de 170 pessoas: 80 homens e 90 mulheres. Cada indivíduo 
respondeu ao questionário uma única vez, e tal controle foi realizado por meio da identificação obrigatória do endereço eletrônico do respondente.

O tratamento e a análise dos dados foram essencialmente quantitativos, com utilização do software estatístico SPSS - Statistical Package for Social Sciences. O construto risco percebido foi mensurado a partir da escala propos- ta por Peter e Tarpey (1975), adaptada à realidade das compras pela Internet. $\mathrm{O}$ risco total foi calculado pelo somatório dos scores de cinco dimensões de risco, que, por sua vez, foram calculadas pela multiplicação da probabilidade de perda/prejuízo com a importância que lhe foi atribuída pelos respondentes, representadas pela fórmula:

$$
\mathrm{OPR}_{\mathrm{\jmath}}=\mathrm{f} \sum_{\mathrm{i}=1}^{\mathrm{n}}\left(\mathrm{PL}_{\mathrm{ij}} \cdot \mathrm{IL}_{i j}\right)
$$

Onde $\mathrm{OPR}_{\mathrm{j}}=$ ris co percebido total na compra pela Internet na situação proposta (j)

$\mathrm{j}=$ situação de compra hipotética proposta ao respondente

$\mathrm{i}=$ dimensão/tipo de risco apresentada

$\mathrm{PLij}_{\mathrm{ij}}=$ probabilidade de perda/prejuízo i para a compra $\mathrm{j}$

$\mathrm{IL}_{\mathrm{ij}}=$ importância da perda/prejuízo i para a j

$\mathrm{n}=$ dimensões/tipos de risco

Figura 2 - Modelo adaptado de mensuração do risco percebido nas compras pela Internet Fonte: Traduzido e adaptado de Peter e Tarpey $(1975$, p. 30).

A probabilidade foi avaliada por uma escala intervalar de classificação somada de sete pontos, variando de "extremamente improvável" a "extremamente provável", com ponto central "nem um nem outro - cerca de 50\%". A importância foi mensurada por uma escala intervalar de classificação somada de sete pontos, variando de "extremamente sem importância" a "extremamente importante", com ponto central "nem importante nem sem importância".

Foram avaliadas cinco dimensões/tipos de risco percebido: financeiro, desempenho, psicológico, social e tempo/conveniência. O risco físico, presente na escala original de Peter e Tarpey (1975), não foi considerado nesta pesquisa, uma vez que a Internet não representaria, segundo Alvares (2004), ameaça à integridade física ou à saúde do consumidor.

A composição das questões correspondentes às dimensões do risco percebido foi inspirada em proposições e escalas propostas pela literatura concernente ao tema, especialmente em Kovacks e Farias (2001; 2003). Cada dimensão foi mensurada por dois indicadores, conforme apresentado no quadro 1.

\begin{tabular}{|c|c|}
\hline Ris co Percebido & Indicadores \\
\hline \multirow[t]{2}{*}{ Financeiro } & a. Possibilidade de interceptação de dados financeiros; e \\
\hline & b. Prejuízo financeiro provocado pela impossibilidade de barganha. \\
\hline \multirow[t]{2}{*}{ Des empenho } & a. Possibilidade de que o produto/s erviço não ofereça os benefícios esperados; e \\
\hline & $\begin{array}{l}\text { b. Dano sofrido pelo produto caso trans portado de forma inadequada (requer confiança } \\
\text { de que o varejista entregará o produto com a mesma qualidade prometida). }\end{array}$ \\
\hline \multirow[t]{2}{*}{ Psicológico } & a. Arrependimento da compra efetuada; e \\
\hline & b. Comprometimento da auto-imagem se a transação eletrônica não for bem sucedida. \\
\hline \multirow[t]{2}{*}{ Social } & a. Julgamento de terceiros pela atitude de compra pela Internet; e \\
\hline & b. Invasão de privacidade e divulgação de dados pessoais. \\
\hline \multirow[t]{2}{*}{ Tempo/conveniência } & a. Possibilidade de não cumprimento do prazo de entrega pela empresa; e \\
\hline & b. Demora em caso de necessidade de trocas. \\
\hline
\end{tabular}




\subsection{Método de análise}

A primeira fase da análise de dados correspondeu à avaliação dos supostos paramétricos. Verificou-se, a partir da prova de "Kolmogorov-Smirnov", que nem todas as variáveis ajustavam-se à curva normal ao nível de significação de 0,05 . As amostras também foram submetidas ao teste de Levene para avaliação da homoscedasticidade e, ao mesmo grau de significação, refutou-se a hipótese nula de homogeneidade das variâncias. Em casos como esse, de não cumprimentos dos supostos paramétricos, Bisquerra, Sarriera e Martinez (2004), sugerem a aplicação de provas não paramétricas.

A fim de avaliar a existência de diferenças significativas relativas às dimensões de riscos percebidos entre os grupos de homens e mulheres, testes comparativos foram efetuados pela prova não paramétrica "U de Mann-Whitney" que, como explicam Bisquerra, Sarriera e Martinez (2004, p. 176), "é uma das principais provas para comparar grupos com dados independentes". Nesse caso, a hipótese nula era a "não existência de diferenças significativas entre os dois grupos", ou ainda que "as diferenças observadas seriam fruto do acaso".

Estatísticas descritivas, incluindo médias e medianas, também foram contempladas na análise a fim de avaliar quais as dimensões de risco percebido foram mais significativas na percepção dos homens e das mulheres analisados, qual dos grupos percebe o risco das compras pela Internet de maneira mais intensa, e qual a dimensão de risco mais representativa para a amostra pesquisada. Testes complementares com outras variáveis foram realizados pela prova não paramétrica "Kruskal-Wallis".

\section{Apresentação e análise dos dados}

\subsection{Perfil da amostra}

Com um total de 170 respon- dentes válidos, a amostra foi composta por 90 mulheres $(52,9 \%)$ e 80 homens $(47,1 \%)$. O grupo etário predominante na amostra foi o de 18 aos 35 anos $(78,9 \%)$, com maior concentração na faixa de 26 a 35 anos (46,5\%). Dos respondentes, $15,9 \%$ estão na faixa de 36 a 45 anos, $4,1 \%$ na de 46 a 55 anos, e $1,2 \%$ têm 56 anos ou mais.

Com relação ao grau de escolaridade, a pesquisa contemplou uma amostra qualificada, com ênfase para os $81,8 \%$ dos entrevistados com, no mínimo, ensino superior completo: $25,3 \%$ cursam mestrado, $20,7 \%$ têm ensino superior completo, $12,9 \%$ são especialistas, $8,2 \%$ cursam especialização, $6,5 \%$ são mestres, 5,3\% cursam doutorado e 2,9 são doutores. Entre os 18,2\% não graduados, $11,8 \%$ estão cursando uma graduação; 3,5\% são desistentes do ensino superior; e 2,9\% têm o ensino médio completo como última formação.

A amostra contemplou respondentes de 16 estados e 44 municípios brasileiros e, inclusive, 1 que reside no exterior (Califórnia - EUA), amplitude esta que foi possibilitava pela coleta de dados via Internet. A maior parte dos respondentes $(62,9 \%)$ reside no Paraná; 8,8\% em São Paulo; 5,3\% em Minas Gerais; $4,7 \%$ no Rio de Janeiro; 3,5\% na Bahia e em Santa Catarina; 2,8\% no Rio Grande do Sul; 2,4\% em Pernambuco; $1,2 \%$ no Ceará; e os outros $4,7 \%$ incluem Acre, Alagoas, Distrito Federal, Espírito Santo, Goiás, Rondônia, Sergipe e Califórnia. Residem em Curitiba 53,5\%,; seguidos de 4,1\% no Rio de Janeiro; 3,5\% em Salvador e São Paulo; 2,9\% em Belo Horizonte e São José dos Pinhais; e outros 39 municípios completam os $29,4 \%$ restantes.

Com respeito à intensidade de horas semanais de acesso à Internet, a maioria dos respondentes $(27,6 \%)$ revelou estar conectado por mais de 20 horas semanais; $27,1 \%$ de 6 a 10 horas; $20,6 \%$ de 1 a 5 horas; $11,8 \%$ de 16 a 20 horas; $11,2 \%$ de 11 a 15 horas; e apenas $1,8 \%$ por menos de uma hora por semana. 
Do total de respondentes, foram retirados da amostra aqueles que revelaram não ter realizado nenhuma compra de produtos e/ou contratação de serviços pela Internet nos últimos seis meses antecedentes à pesquisa. Entre os respondentes válidos, mais da metade $(52,4 \%)$ apresentou uma frequência de compra de 2 a 5 vezes no período analisado; $21,2 \%$ haviam experienciado a compra pela internet uma única vez; $15,9 \%$ de 6 a 10 vezes, $5,9 \%$ mais de 15 vezes; e $4,7 \%$ de 11 a 15 vezes.

\subsection{Resultados}

Os testes comparativos realizados pela prova não paramétrica " $U$ de
Mann-Whitney" revelaram que as diferenças nas percepções de homens e mulheres quanto ao risco nas compras pela Internet foram significativas apenas na dimensão de risco de desempenho, percebido pelas mulheres com mais intensidade. O risco de desempenho, também conhecido como funcional, está ligado à possibilidade de que o produto adquirido não esteja de acordo com expectativas do consumidor em termos de funcionamento e/ou benefícios esperados. Nas demais dimensões e no risco total, não houve diferenças estatisticamente significativas entre os dois grupos quanto à significação de 0,05 , como demonstra o quadro 2 a seguir.

\begin{tabular}{|l|c|c|c|}
\hline Dimensão de risco & Score masculino & Score feminino & Sig. \\
\hline Conveniência & 53,9375 & 58,8 & 0,1529 \\
\hline Desempenho & 48,8125 & 54,8556 & $0,0320^{*}$ \\
\hline Financeiro & 48,8 & 51,6 & 0,4744 \\
\hline Social & 38,0375 & 42,4778 & 0,1704 \\
\hline Psicológico & 34,025 & 35,8111 & 0,3785 \\
\hline Total & 223,6125 & 243,5444 & 0,1167 \\
\hline
\end{tabular}

Quadro 2 - Scores e teste "U de Mann-Whitney" para dimensões do risco percebido * significante ao nível de $\mathrm{p}<0,05$. Fonte: os autores.

Os dados da pesquisa apresentados no quadro 3 também apontam que as mulheres pesquisadas revelaram perceber mais intensamente o risco total e em todas as dimensões, embora apenas no risco de desempenho essa diferença tenha sido estatisticamente significativa. A ordem de intensidade nas dimensões não se alterou entre os grupos. O risco de tempo/conveniência foi o percebido com maior intensidade pela amostra, e o psicológico foi o menos representativo para ambos os grupos na situação proposta. O financeiro foi o que apresentou menor discrepância entre os dois estratos, com um grau de significância 0,4744 .

Analisando cada indicador separadamente, a prova " $U$ de Mann-Whitney" revelou diferenças significativas entre os gêneros nos itens (a) invasão de privacidade e divulgação de dados financeiros (uma das facetas do risco social) e (b) expectativa não correspondida (risco de desempenho) quanto à significância de 0,05 , conforme segue: 


\begin{tabular}{|l|l|c|c|c|c|c|}
\hline \multirow{2}{*}{$\begin{array}{c}\text { Dimens ão de ris co } \\
\text { percebido }\end{array}$} & \multicolumn{1}{|c|}{ Indicadores } & \multicolumn{2}{c|}{ Masculino } & \multicolumn{2}{c|}{ Feminino } & \multirow{2}{*}{ Sig. } \\
\cline { 3 - 6 } & & Posição & Score & Posição & Score & \\
\hline Tempo/conveniência & Demora em efetuar trocas & $1^{\circ}$. & 28,9375 & $1^{\circ}$. & 30,5444 & 0,3839 \\
\hline Financeiro & $\begin{array}{l}\text { Interceptação de dados } \\
\text { financeiros }\end{array}$ & $2^{\circ}$. & 27,0125 & $2^{\circ}$. & 29,1111 & 0,2952 \\
\hline Tempo/conveniência & Prazo de entrega & $3^{\circ}$. & 25,0000 & $4^{\circ}$. & 28,2556 & 0,0801 \\
\hline Desempenho & Dano no transporte & $4^{\circ}$. & 24,9625 & $6^{\circ}$. & 27,1778 & 0,1145 \\
\hline Social & $\begin{array}{l}\text { Invasão de privacidade e } \\
\text { divulgação de dados financeiros }\end{array}$ & $5^{\circ}$. & 24,7000 & $3^{\circ}$. & 28,5000 & $0,0482^{*}$ \\
\hline Desempenho & Expectativa não correspondida & $6^{\circ}$. & 23,8500 & $5^{\circ}$. & 27,6778 & $0,0363 *$ \\
\hline Financeiro & Impossibilidade de barganha & $7^{\circ}$. & 21,7875 & $7^{\circ}$. & 22,4889 & 0,6901 \\
\hline Psicológico & Arrependimento & $8^{\circ}$. & 19,4000 & $8^{\circ}$. & 21,7222 & 0,1654 \\
\hline Psicológico & Comprometimento da autoimagem & $9^{\circ}$. & 14,6250 & $9^{\circ}$. & 14,0889 & 0,8719 \\
\hline Social & Julgamento de terceiros & $10^{\circ}$. & 13,3375 & $10^{\circ}$. & 13,9778 & 0,4183 \\
\hline
\end{tabular}

Quadro 3 - Scores, posição e teste "U de Mann-Whitney” para indicadores das dimensões do risco percebido * significante ao nível de $\mathrm{p}<0,05$. Fonte: os autores.

$\mathrm{O}$ quadro 3 também ilustra que, embora as mulheres tenham percebido mais intensamente o risco percebido em quase todas as dimensões, a ordem de classificação atribuída (calculada com base nos scores) alterou-se entre os grupos. A preocupação com o desperdício de tempo provocado por uma possível demora em efetuar trocas foi indicada como o mais relevante por homens e mulheres. Em segundo lugar, ficou o receio da interceptação dos dados financeiros. Entre os homens, o risco relacionado à possibilidade de demora na entrega dos produtos ficou em terceiro lugar, mas, entre as mulheres, essa preocupação cedeu sua posição para a invasão de privacidade e divulgação de dados pessoais (que para os homens ganhou a quinta posição). $\mathrm{O}$ receio de que o produto sofra danos no transporte ocupou quarta colocação entre os homens e sexta pelas mulheres. Para elas, a preocupação de que o produto não corresponda às expectativas foi mais relevante (quarta colocação), e ficou em quinto entre os homens. A ordem dos quatro últimos indicadores (impossibilidade de barganha, arrependimento, comprometimento da autoimagem e julgamento de terceiros) não se alternou entre os diferentes gêneros.

A fim de contribuir para uma melhor compreensão do fenômeno es- tudado, foram realizados testes não paramétricos "Kruskal-Wallis" complementares, com o intuito de verificar a influência de outras variáveis na percepção de risco dos respondentes, tais como idade, grau de escolaridade, frequência de horas semanais de acesso à Internet e a intensidade de compras realizadas pelo canal no período considerado.

Não houve significância estatística entre os diferentes grupos etários, o que se repetiu com a intensidade de horas semanais de acesso à Internet, com a quantidade de compras realizadas pela Internet no período determinado, bem como quanto ao grau de escolaridade quando os dez grupos foram analisados separadamente. Entretanto, a variável escolaridade foi testada também com o agrupamento em dois clusters: o primeiro grupo, denominado de "não pós-graduados", formado por 80 pessoas (de ensino médio completo à especialização incompleta); e o segundo grupo, formado por 90 "pós-graduados" (de especialização à doutorado). Essa formação foi escolhida tendo em vista uma divisão mais equitativa possível da amostra. Nesse caso, as diferenças revelaramse significativas nas percepções de risco financeiro $(p=0,047)$, social $(p=0,007)$ e psicológico $(\mathrm{p}=0,014)$. À exceção do risco de tempo/conveniência, o primeiro grupo percebeu com mais intensidade as demais quatro dimensões. 


\section{Considerações finais}

Os resultados da pesquisa apontaram, em confluência com o que propõe a literatura, para uma maior aversão ao risco pelas mulheres, que o perceberam mais intensamente na situação proposta em todas as dimensões e no somatório final. A despeito disso, a relevância estatística de diferenças entre os grupos foi comprovada apenas em uma das dimensões: o risco de desempenho, carregado principalmente pelo indicador relacionado a uma possível expectativa não correspondida, como demonstrou a análise em separado de cada uma das dimensões.

Vale lembrar que o risco de desempenho pode ser desencadeado em função da impossibilidade de experimentação do produto adquirido, ou seja, como não é possível experimentar, tocar ou sentir o que se está comprando, o consumidor pode perceber o risco de comprar um produto que não esteja de acordo com suas expectativas, situação que o coloca em necessidade de confiar que o varejista entregará o produto conforme o esperado. Essa constatação parece coerente com a assertiva de Silva et al. (2000, p. 56), pela qual se considera que há "características intrínsecas das mulheres, que as fazem preferir o comércio convencional, em que podem tocar, sentir, experimentar o produto".

Além disso, há coerência com as características peculiares às compradoras apontadas por Underhill (1999; 2009): avaliação mais criteriosa das alternativas, cautela, bem como a relevância da função social das compras.

Outra constatação da pesquisa foi que a ordem de classificação da intensidade das dimensões não se alterou entre os diferentes gêneros, sendo que o tipo de risco percebido com mais intensidade, por ambos os grupos, foi o de tempo/ conveniência, seguido do risco financeiro, como previa a literatura e em consonância com outras pesquisas realizadas e anteriormente mencionadas.
Já quando os indicadores foram analisados separadamente, tal ordenamento apresentou dessemelhanças entre os grupos. Evidenciou-se também que a invasão de privacidade e divulgação de dados pessoais (risco social) é significativamente mais relevante para as mulheres do que para os homens. Entretanto, como os scores do risco de julgamento de terceiros (o segundo componente do risco social) foram muito próximos na avaliação dos grupos de cada gênero, a diferença global dessa dimensão não se revelou significativa.

Possíveis limitações deste estudo estão relacionadas à realização de técnicas de amostragem não probabilísticas e de testes não paramétricos, que restringem a possibilidade de generalização dos resultados para o restante da população. Além disso, a principal variável analisada - gênero - não revelou grande impacto na percepção do risco percebido nas compras pela Internet, na amostra estudada. Entretanto, esta pesquisa buscou identificar, entre os dados analisados, outras variáveis que pudessem indicar alguma relevância, tendo encontrado o grau de escolaridade com significância estatística em três das cinco dimensões analisadas. Diante disso, como indicação para pesquisas futuras, sugere-se controlar como o impacto de outras variáveis - como, por exemplo, formação, renda, classe social, estilo de vida ou a combinação destas - atua na percepção de risco nas compras pela Internet, a fim de contribuir para uma melhor compreensão do fenômeno estudado.

\section{Referências}

ALVARES, L. Quando risco e sensações encontram-se na teia: uma investigação empírica da relação entre a busca de sensações e o risco percebido em compras pela Web. Rio de Janeiro, 2004. 250f. Tese (Doutorado em Administração) - Universidade Federal 
do Rio de Janeiro - UFRJ, Instituto COPPEAD de Administração.

AMARAL, B.L.; NIQUE, W. E-Commerce: Atributos Determinantes na Utilização da Internet como Canal de Compra. In: ENCONTRO NACIONAL DA ANPAD. 24. 2000, Florianópolis. Anais... Santa Catarina: XXIV ENANPAD, 2000. 1 CD-.ROM.

BACELLAR, F.C.; GOUVEIA, T.M.O.A; MIRANDA, L.C.Homens vão às compras no supermercado: atitudes, opiniões e hábitos. In: SEMINÁRIOS EM ADMINISTRAÇÃO FEA - USP.9. 2006, São Paulo. Anais... São Paulo: IX SEMEAD/FEA-USP, 2006. Disponível em: $\quad<$ http://www.ead.fea.usp.br/ Semead/9semead/resultado_semead/ trabalhosPDF/171.pdf $>$ Acesso em: 5 mai. 2012.

BISQUERRA, R.; SARRIERA, J. C; MARTINEZ, F. Introdução à estatística: enfoque informático com o pacote estatístico SPSS. Porto Alegre: Artes Médicas, 2004.

BLACKWELL, R. D.; MINIARD, P.W. ENGEL, J. F.; Comportamento do consumidor. 9.ed. São Paulo: Thomson, 2005.

BRASIL, V. S.; SAMPAIO, C. H.; PERIN, M. G. A relação entre a intangibilidade, o risco percebido e o conhecimento. Revista de Ciências da Administração, v. 10, n. 21, p. 31-53, mai./ago. 2008.

CATERALL, M.; MACLARAN, P. Gender perspectives in consumer behaviour: an overview and future directions. Marketing Review, v.2, n.2 p.405-425, 2002.
CHEN, Y., BARNES, S. Initial trust and online buyer behavior. Industrial Management \& Data Systems, p.2136, 2007.

CORDEIRO, A. T.; SILVEIRA, L. C.; BENEVIDES, V.M.F. Decisão de compra na Internet e percepção de risco: uma investigação empírica sobre os riscos percebidos pelos consumidores e seus atenuantes. In: ENCONTRO NACIONAL DA ANPAD. 28. 2004, Curitiba. Anais... Paraná: XXVIII ENANPAD, 2004. 1 CD-.ROM.

E-BIT. Disponível em: <http://www. ebit.com.br> Acesso em: 10. mai. 2012.

FARLEY, F. World of the type T personality. Psychology Today. p.4652, may 1986.

G1. Apenas $6 \%$ das brasileiras compram pela internet, diz Ibope. 05. mar. 2010. Disponível em: <http://g1.globo.com/ Noticias/Tecnologia/0,,MUL15180516174,00-APENAS+DAS+BRASILEI RAS+COMPRAM+PELA+INTERNE T+DIZ+IBOPE.html $>$ Acesso em: 12 . mai. 2012.

GREWAL, D. et al. The moderating effects of message framing and source credibility on the price-perceived risk relationship. Journal of Consumer Research. v. 21, n.1, p.145-153, jun, 1994.

HAIR JR., J.F. et al. Fundamentos de métodos de pesquisa em administração: Porto Alegre: Bookman, 2005.

HERNANDEZ, J.M.C. Entendendo melhor o processo de decisão de compra na Internet: um estudo empírico. Ibmec: São Paulo. 2002. 
Disponível em: $\quad<$ http://www. ibmecsp.edu.br/ pesquisa/download. php?recid=1225> Acesso em: 05 mai. 2012.

.Porque algumas pessoas compram mais que outras pela Internet: o papel do conhecimento e do risco percebido. In: ENCONTRO NACIONAL DA ANPAD. 27. 2003, Atibaia. Anais... São Paulo: XXVII ENANPAD, 2003. 1 CD-.ROM.

HOR-MEYLL, L. F. Construção de uma escala para mensurar o risco percebido na compra online de um serviço hoteleiro. In: ENCONTRO NACIONAL DA ANPAD. 28. 2004, Curitiba.Anais... Paraná: XXVIII ENANPAD, 2004. 1 CD-.ROM.

KOTLER， P.; KELLER， K. L. Administração de marketing. São Paulo: Pearson Prentice Hall, 2006.

KOVACS, M.H.; BARBOSA, M.L.A. A atmosfera do e-tailing, riscos percebidos e a satisfação do consumidor: proposição de um esquema teórico para e-commerce com base no modelo s-o-r. In: ENCONTRO NACIONAL DA ANPAD. 29. 2005, Brasília. Anais... Distrito Federal: XXIX ENANPAD, 2005. 1 CD-.ROM.

KOVACS, M.H.; FARIAS, S.A. Riscos percebidos e meios de compra: a dualidade Internet versus consumidores on-line. In: ENCONTRO NACIONAL DA ANPAD. 24. 2000, Florianópolis. Anais... Santa Catarina: XXIV ENANPAD, 2000. 1 CD-.ROM.

Comércio eletrônico: há diferentes dimensões de riscos percebidos entre os usuários da Internet que com- pram e os que nunca compraram por este meio?. In: ENCONTRO NACIONAL DA ANPAD. 25. 2001, Campinas. Anais... São Paulo: XXV ENANPAD, 2001. 1 CD-.ROM.

KOVACS, M.H.; ESPÍRITO SANTO, T.M.V. Entre o Risco Percebido e a Satisfação com as Compras pela Internet Há Mais Transformações de que Pode Supor a Nossa Vã Teoria. In: ENCONTRO NACIONAL DA ANPAD. 32. 2008, Rio de Janeiro. Anais... Rio de Janeiro: XXXII ENANPAD, 2008. 1 CD-.ROM.

LASCH, E. Do you trust the web? Ohio CPA Journal. v. 57, n.4, p.8-10, oct-dec, 1998.

LING, K. C. et al. Perceived risk, perceived technology, online trust for the online purchase intention in Malaysia. International Journal of Business and Management, v. 6, n.6, p. 167-182, jun 2011.

LYNCH, D. C.; LUNDQUIST, L. Dinheiro digital: o comércio na Internet. Rio de Janeiro: Campus, 1996. MOWEN, J.C.; MINOR, M.S. Comportamento do consumidor. São Paulo: Prentice Hall, 2003.

PERETTI, C. (Org). Filosofia do gênero em face da teologia: espelho do passado e do presente em perspectiva do amanhã. Curitiba: Champagnat, 2011.

PETER, J. P.; TARPEY, L.X. A comparative analysis of three consumer decision strategies. Journal of Consumer Research, v.2, p.29-37, jun, 1975.

PETER, J. P.; RYAN, M. An investigation of perceived rat the brand 
RELAÇÕES DE GÊNERO NO COMPORTAMENTO DE COMPRA PELA INTERNET: ESTUDO DAS DIMENSÕES DO RISCO PERCEBIDO

level. Journal of Marketing Research, v. 13, p-184-188, may, 1976.

ROSELIUS, T. Consumer rankings of risk reduction methods. Journal of Marketing, v. 35, p-56-61, jan, 1971.

SILVA, A.C.E et al. Um olhar sobre o comportamento de compra dos usuários da Internet. Caderno de pesquisas em Administração, São Paulo, v. 07, n. 3, p.44-57, jul-set, 2000. Disponível em: $<$ http://www.ead.fea.usp.br/cad-pesq/ arquivos/v07-3ART04.pdf> Acesso em: 05 mai. 2012.

SOLOMON, M. R. O comportamento do consumidor: comprando, possuindo e sendo. Porto Alegre: Bookman, 2008. UNDERHILL, P. Vamos às compras: a ciência do consumo. Rio de Janeiro, Elsevier, 1999.

Vamos às compras: a ciência do consumo nos mercados globais. 2 ed. rev. amp. Rio de Janeiro: Elsevier, 2009. 
